\title{
ATUAÇÃO DA FISIOTERAPIA NA PREVENÇÃO DE LESÕES NO VOLEIBOLI
}

\author{
PERFORMANCE OF PHYSIOTHERAPY IN THE PREVENTION OF INJURIES IN \\ VOLLEYBALLI
}

Jéssica da Silva de Sousa ${ }^{1}$

Tairo Vieira Ferreira ${ }^{2}$

RESUMO: O voleibol i é um esporte que, requer grande esforço físico, onde sua prática resulta em impactos excessivos em determinadas partes do corpo, devido aos inúmeros saltos realizados pelos atletas, durante uma partida e/ou durante os treinamentos, podendo ocasionar lesões. Esse estudo possui por tema, refletir sobre a atuação da Fisioterapia na Prevenção de Lesões no Voleibolı, tendo-se como área de concentração a Fisioterapia Traumato-Ortopédica Funcional. O Objetivo Geral encontra-se disposto em: Verificar a importância que há na intervenção da Fisioterapia, frente a prevenção de lesões em atletas de Voleibolı. Metodologia: Pesquisa bibliográfica e qualitativa, com intuito de buscar informações fundamentadas em livros, artigos, dissertações, trabalhos acadêmicos de tese e monografias, no que tange a finalidade de se desenvolver uma revisão da literatura sobre o tema em questão, no sentido de fazer uma avaliação crítica dos estudos e fundamentação científica do trabalho. Tendo-se embasado nos autores desse estudo,pode-se compreender que a atuação da Fisioterapia preventiva em esportistas praticantes do Voleibol I não somente pode melhorar o desempenho esportivo, mas também oferecer ferramentas que contribuem para a longevidade da vida esportiva desse atleta. Ao término desse estudo, pode-se concluir que a Fisioterapia Preventiva no campo esportivo, mostra-se mostra eficiente não apenas na reabilitação das lesões, como também como instrumento de prevenção das mesmas, levando-se em consideração que esse campo fisioterapêutico tornase foi eficaz para minimizar o índice de lesões nos atletas, de forma especial e objeto desse estudo, nos praticantes de Voleibol I, proporcionando para o esse público, mais segurança ao desempenhar esse esporte.

Palavras-Chave: Voleibol I. Atletas. Fisioterapia. Prevenção. Lesões.

ABSTRACT: Volleyball $\mathrm{I}$ is a sport that requires great physical effort, where its practice results in excessive impacts on certain parts of the body, due to the numerous jumps

\footnotetext{
' Acadêmica do ro $^{\mathrm{o}}$ período do Curso de Fisioterapia, Faculdade UniBrás - Unidade Rio Verde. Email: Jessicasousa_silva@outlook.com.

2 Professor do Curso de Fisioterapia, da Faculdade UniBrás - Unidade Rio Verde. E-mail: tairo@faculdadeobjetivo.com.br.
} 
performed by athletes, during a match and/or during training, which can cause injuries. The theme of this study is to reflect on the role of Physiotherapy in the Prevention of Injuries in Volleyballi, having as its area of concentration Functional TraumatoOrthopedic Physiotherapy. The General Objective is arranged in: Verify the importance of the intervention of Physiotherapy, facing the prevention of injuries in Volleyball athletesı. Methodology: Bibliographic and qualitative research, in order to seek information based on books, articles, dissertations, academic thesis and monographs, with regard to the purpose of developing a literature review on the subject in question, in order to make a critical evaluation of the studies and scientific foundation of the work. Based on the authors of this study, it can be understood that the performance of preventive Physiotherapy in athletes practicing Volleyball I can not only improve sports performance, but also offer tools that contribute to the longevity of this athlete's sports life. At the end of this study, it can be concluded that Preventive Physiotherapy in the sports field is shown to be efficient not only in the rehabilitation of injuries, but also as an instrument for preventing them, taking into account that this physiotherapy field becomes it was effective to mimic the injury rate in athletes, in a special way and object of this study, in Volleyball I practitioners, providing this public with more security when playing this sport.

Keywords: Volleyball I. Athletes. Physiotherapy. Prevention. Injuries.

\section{INTRODUÇÃO}

O voleibol é um esporte que, como todos os outros, requer esforço físico, sendo que sua prática resulta em impactos excessivos em determinadas partes do corpo, devido justamente aos inúmeros saltos realizados pelos atletas durante uma partida e/ou durante os treinamentos, podendo ocasionar lesões.

Frente a essas considerações, esse estudo possui por tema, refletir sobre a atuação da Fisioterapia na Prevenção de Lesões no Voleibolı, tendo-se como área de concentração a Fisioterapia Traumato - Ortopédica Funcional.

O campo da Fisioterapia Esportiva representa uma das especialidades do profissional da fisioterapeuta, tendo-se em vista esta inserção e atuação efetiva encontrase inserida no contexto das modalidades e passa invariavelmente pelo próprio desenvolvimento, estruturação e consolidação de cada modalidade, gerando reflexo na profissionalização da atenção aos atletas e aos coletivos.

O problema que envolve esse trabalho, buscou responder a seguinte problemática: De que maneira a atuação da Fisioterapia pode atuar na prevenção de Lesões em atletas do Voleibol I? 
Assim, uma hipótese a ser considerada diante esse questionamento é o de que nos últimos anos, vem aumentando a atuação do Fisioterapeuta na área de disfunções Musculoesqueléticas derivadas de traumas esportivos, onde atletas do Voleibol i que iniciam a carreira precocemente estão propensos a possíveis alterações posturais, lesões e dores que podem variar conforme o tempo e intensidade do treino e provocar impacto negativo no desempenho esportivo e na qualidade de vida.

O objetivo Geral desse trabalho culmina em: Verificar a importância que há na intervenção da Fisioterapia, frente a prevenção de lesões em atletas de Voleibolı. Já os Objetivos Específicos que norteiam esse trabalho são: - Avaliar a eficácia do tratamento fisioterapêutico durante o período de competições do Voleibo; - Analisar quais são os principais métodos de preparação física de cada sessão de treinamentos realizados pelo Fisioterapeuta; -Evidenciar a importância da fisioterapia para atletas do Voleibol I; Apoiar-se da literatura que trata dessa temática, para que sejam comprovadas de forma verídica, acerca da importância desse trabalho.

Portanto, esse trabalho se justifica com a intenção de apontar alguns dos estudos realizados em Fisioterapia Esportiva e seus principais achados, envolvendo asssim, as lesões esportivas, no que tange ao Voleibor.

Este trabalho trata-se de uma revisão da literatura utilizando as bases de dados das plataformas, PEDro, Medline, Lilacs, PubMed, Google Acadêmico, Scielo, Bireme, além de livros.

Foram selecionados artigos de 1996 a 2020, com temas relacionados à a intervenção da Fisioterapia, com enloque na prevenção de lesões em atletas de voleibolı. Sendo os resultados apresentados de forma descritiva.

A pesquisa foi realizada nos idiomas nacional, de Língua Portuguesa, bem como de Língua Inglesa, utilizando-se assim das seguintes palavras-chave: Prevenção; Voleibolı, Fisioterapia, Lesões.

Foram excluídos os estudos que não faziam relação com a fisioterapia preventiva, frente ao tema principal, artigos de revisão sistemática, bem como também artigos que não testavam os protocolos utilizados de fisioterapia preventiva na prática esportiva do Voleibol I. 


\section{BREVE APANHADO HISTÓRICO DO VOLEIBOL}

Quando o Voleibol foi inventado, já haviam outros esportes praticados, porém esportes que envolviam bastante contato físico entre os jogadores. Assim, Willian George Morgan $^{3}$ teve a brilhante ideia de inventar um esporte que tivesse agilidade, força e técnica, porém sem contato físico, para que pudesse preservar os praticantes de lesões e fraturas, a primeira denominação para a modalidade foiMintonette. Partindo dessas concepções, nasce um esporte praticado com as mãos, sem contato físico e que apresenta todas as características que ele buscava praticar no meio esportivo.

De acordo com Matia e Greco (2011, p.5I):

Os primeiros saques do voleibol foram dados pelo professor William Morgan, da YMCAı (Young Men's Christian Association - no Brasil: ACM - Associação Cristã de Moços) em Massachusetts nos Estados Unidos. Em I895, o professor William Morgan criou um jogo chamado de Mintonette. Nele havia a combinação de elementos do basketball, do tênis e do handebol americano (similar ao squash, em vez da raquete, rebatem-se as bolas com as mãos) (MATIA e GRECO, 2oII, p.5I).

Não demorou muito para que o Voleibol se tornasse uma das modalidades mais praticadas no mundo, resultados divulgados pela Associação Cristã de Moços (ACM) por Willian o responsável na época, após o falecimento de Willian a FIVB (Confederação Internacional de Vôlei), assumiu todas as diretrizes do esporte. Por volta de I9I5, o Vôlei foi reconhecido no Brasil, tendo a Confederação Brasileira de Vôlei (CBV) responsável pelos times confederados do país (MATIA e GRECO, 20II).

De acordo Matthlesen (1994) relatos afirmam que o primeiro campeonato nacional de Voleibol no Brasil, só aconteceu em 1944, algumas décadas depois da chegada desse desporto, contando com a participação de seis equipes femininas (vencido por Minas Gerais) e oito masculinas (São Paulo foi o vencedor).

Segundo Matias e Greco (2011, p.5I):

A estrutura amadora do voleibol brasileiro começou a se modificar gradualmente a partir de 1974, com a eleição de Carlos Artur Nuzman para a presidência da Confederação Brasileira de Voleibol (semiprofissionalizou-se de meados da década de 1970 até meados dos anos 1980; a partir do fim dos 1980, ocorreu a profissionalização). Contribuiu para o desenvolvimento do voleibol no Brasil o

\footnotetext{
${ }^{3}$ William George Morgan (187o - 1942), foi o inventor do Voleibol, originalmente chamado "Mintonette", nome derivado do jogo badminton que ele resolveu mudar para melhor refletir a natureza do esporte.
} 
trabalho de diversos dirigentes, treinadores e outros profissionais do esporte (MATIAS e GRECO, 2oII, p.5I).

Desde o surgimento da modalidade até o ano de 2009, o Voleibol passou por constantes adaptações e mudanças comparado as suas origens, a fim de tornar a prática mais relevante para os jogadores, desde a execução dos fundamentos, dimensão da rede relacionada às categorias femininas e masculinas, infrações e novas particularidades que foi caso da inserção do líbero.

Matias e Greco (2011, p.58) descrevem que:

A estrutura amadora do Voleibol brasileiro começou a se modificar gradualmente a partir de 1974, com a eleição de Carlos Artur Nuzman para a presidência da Confederação Brasileira de Voleibol (semiprofissionalizou-se de meados da década de 1970 até meados dos anos 1980; a partir do fim dos anos 1980, ocorreu a profissionalização). Contribuiu para o desenvolvimento do voleibol no Brasil o trabalho de diversos dirigentes, treinadores e outros profissionais do esporte (MATIAS e GRECO, 2011, p.58).

O campeonato mais importante para o Voleibol, são os Jogos Olímpicos que reúne todas as modalidades, com times de todos os países em uma capital sede. O Brasil tem dois títulos na categoria feminina e cinco no masculino, em seguida temos o Mundial de vôlei, depois Liga das Nações que antigamente era denominado Grand Prix. Interno no Brasil tem a Superliga que é disputada entre os times de clubes de todos os estados (MATIAS e GRECO, 20II).

\section{CARACTERÍSTICAS DO VOLEIBOL}

O voleibol é um esporte que vai muito mais além do que apenas fazer com que a bola caia no chão, onde far-se-á importante também levar-se em consideração a complexidade dos fundamentos, bem como a variedade de sistemas táticos presentes na modalidade, que o torna interessante, cada vez mais que é praticado. A técnica aplicada a este desporto o resulta em uma das modalidades mais complexas, em se tratando da execução (LANZA, 2018).

O jogo de voleibol é realizado através de fundamentos determinados como o saque, recepção, levantamento, ataque, bloqueio e defesa. Esse desporto é praticado com duas equipes onde estarão opostas na quadra, e tendo como objetivo marcar o ponto (MARQUES et al., 2007). 
O voleibol é considerado um dos esportes mais explosivos e rápidos disputados atualmente. Suas ações requerem força, potência, agilidade e velocidade, sem mencionar estratégias competitivas elaboradas (LANZA, 2018).

Assim, o Voleibol consiste em uma modalidade disputada por duas equipes com o objetivo de lançar a bola por cima de uma rede, fazendo com que ela atinja o chão do lado adversário, esta prática exige bastante coordenação e sincronia na execução dos fundamentos para bloquear as ações do lado oposto, seguindo dois princípios que são: ataque e defesa, exigindo assim dos atletas habilidade, agilidade e força, o que muitas vezes ocasiona diversas lesões (CBV, 2013).

\section{AS LESÕES NO VOLEIBOL E A IMPORTÂNCIA DA PREVENÇÃO}

Segundo Ferreira (1986) as lesões podem ser conceituadas como um tipo de alteração de um tecido, devido a alguma patologia ou algum trauma, que poderá acarretar a perca da função muscular. As lesões estão divididas e se caracterizam em direitas ou indiretas, parciais ou totais, traumática ou atraumáticas (COHEN e ABDALLA, 2005).

No que se refere as lesões esportivas, em diversas situações são provocadas por métodos inadequados de treinamento, alterações estruturais que sobrecarregam mais determinadas partes do corpo do que outras e muitas dessas lesões também podem ser causadas pelo desgaste crônico e por lacerações, os quais são decorrentes de movimentos repetitivos (overuse) que afetam os tecidos suscetíveis (ANTÔNIO, 20I2).

Contudo, no que se refere as atividades esportivas do Voleibol, assim como qualquer outro esporte, requer esforço físico, onde sua prática contínua resulta em impactos excessivos em determinadas partes do corpo, devido justamente aos inúmeros saltos realizados pelos atletas durante uma partida e/ou durante os treinamentos, podendo ocasionar lesões (CARDOSO, 2005).

Frente a essas informações, Cardoso (2005) corrobora em afirmar que o trabalho de prevenção no voleibol é de fundamental importância para diminuir o índice de lesões, além de garantir que o atleta mantenha-se em atividade por maior tempo possível durante a temporada de competições.

Diante dessas informações pode-se compreender que o aspecto preventivo do tratamento de lesões esportivas como: Entorse; Contusão; Cãibras; Luxação; Fratura por 
estresse; Estiramento e distensão muscular; Tendinite; Fascite; Bursite; dentre outras, onde faz-se de suma importância para a atuação do fisioterapeuta, que necessita assim, redirecionar seu foco de atenção, das lesões já instaladas, para situações de risco, por meio de avaliações individualizadas e acompanhamento dos atletas, o Fisioterapeuta conseguirá identificar desequilíbrios musculares, alterações posturais, e déficits biomecânicos importantes e que necessitem de intervenção. Dessa forma, o aspecto preventivo possui por intenção primordial, a execução segura e eficiente de um gesto esportivo que vai garantir maior desempenho e rendimento ao atleta de alto nível (ALVES, et al., 2006).

Para Resende et al., (2014) a prevenção de lesões esportivas no Voleibol, abarca uma ampla relevância para a execução segura e eficiente de um gesto esportivo ou ainda para garantir o elevado desempenho desse profissionais de alto nível, aumento de sua longevidade esportiva, máxima extração de seu rendimento, bem como garantindo assim, maiores conquistas inerentes a esse esporte, tendo-se em vista que são tarefas que exigem trabalho árduo e que demandam um treinamento seguro, levando-se em consideração que uma lesão necessita ser prevenida, para que não inviabilize o andamento dos treinos ou ainda não culmine em perdas significativas nas conquistas adquiridas.

\section{A IMPORTÂNCIA DA ATUAÇÃO DO FISIOTERAPEUTA NA ASSISTÊNCIA DO VOLEIBOL I}

Segundo Talma (2009) diversos são os benefícios proporcionados as pessoas praticantes do Voleibol I, porém faz-se importante pontuar que esta atividade esportiva, expõe o jogador a lesões desportivas, que afetam principalmente o sistema osteomioarticular à medida que os atletas buscam a superação dos seus limites.

A assistência realizada pelo fisioterapeuta esportivo é refletida em todos os domínios de sua prática, com participação em todas as funções possíveis de serem ocupadas. Atualmente, ainda permanecem discussões quanto ao papel e à formação necessária de cada profissional de saúde na área esportiva. Mesmo defronte a questionamentos acerca do real papel de cada profissional, a equipe de saúde, incluindo o fisioterapeuta, que atende ao atleta, desenvolve seu trabalho profissional em quatro grandes domínios: prevenção, atendimento emergencial, reabilitação e retorno do atleta à atividade (SILVA et al., 20II). 
Gilchrist et al., (2008) pontuam sobre a eficácia de um programa denominado PEP (Programa Preventivo Para Evitar Lesões E Melhorar A Performance) na prevenção de lesões do LCA (Ligamento Cruzado Anterior), tendo-se em vista que esse treinamento neuromuscular e proprioceptivo foram utilizados como maneira de intervenção, demonstrando-se assim, mudanças precoces na força, equilíbrio e propriocepção. Para os autores, esse programa mostrou benéfico frente ao seu treinamento, para minimizar os atletas de futuros danos físico.

Dessa forma, a Fisioterapia esportiva se ampara de técnicas na prevenção de lesões, onde um dos métodos mais utilizados culmina no treinamento proprioceptivo, que consiste em um programa de treinamento neuromuscular, ao qual na maioria dos casos, demonstra ser eficaz na minimização da incidência de lesões em atletas praticantes do Voleibol. Esse treinamento comprovou ser eficiente no aprimoramento do equilíbrio, mas ainda há poucos estudos que mostram seu efeito no senso de posição articular, quando o programa é incorporado no treinamento de atletas (GILCHRIST et al., 2008).

Contudo, pode-se compreender que o objetivo maior da fisioterapia esportiva culmina em proporcionar meios para tentar prevenir lesões, melhorar desempenho do praticante, além de auxiliar na recuperação de lesões, possibilitando o retorno mais precoce as atividades (BEIJSTERVELDT et al., 2013).

Para Resende et al., (2014) o campo da Fisioterapia esportiva no Voleibol I busca prevenir e reduzir as taxas de lesões nos atletas, levando-se em consideração o treinamento para prevenção, incorporado a preparação física reduz a incidência de lesões esportivas. Dentro dessa concepção, os atletas que praticam esse esporte, em suma, buscam alternativas para evitar ou minimizar ao máximo o risco de lesões. Assim, os atletas praticantes do Voleibol, bsucam o auxílio de um fisioterapeuta esportivo, na intenção de prever possíveis danos ao bem-estar físico e psicológico dos mesmos, onde esse profissional irá os auxiliar, orientar e nortear atividades e ações técnicas para que sejam precavidos futuras contusões, favorecendo-se assim, uma vivência esportiva mais eficaz minimizando os riscos de lesões (RESENDE et al., 2014). 


\section{CONCLUSÕES}

O respectivo trabalho buscou contribuir com significativos conhecimentos acerca de apontar sobre o papel da fisioterapia no que se refere à aplicação dos métodos e técnicas de prevenção de lesões em esportivas do Voleibol I.

Portanto, os estudos aqui embasados em suma, destacaram que as atividades da Fisioterapia preventiva aplicadas aos praticantes do Voleibol I não somente podem melhorar o desempenho esportivo, mas também oferece meios que contribuam para a longevidade da vida esportiva desse atleta.

Assim, por meio desse estudo pode-se concluir o quão a Fisioterapia Esportiva se mostra eficiente não apenas na reabilitação das lesões, como também como instrumento de prevenção das mesmas, levando-se em consideração que esse campo fisioterapêutico tornase foi eficaz para minimizar o índice de lesões nos atletas, de forma especial e objeto desse estudo, nos praticantes de Voleibol I, proporcionando para o esse público, mais segurança ao desempenhar esse esporte.

Esse estudo acredita ser uma ferramenta para somar na escassa literatura contemporânea que aborda toda temática que trata acerca da conduta fisioterápica na prevenção de lesões provocadas por atletas praticantes do Voleibol I.

Contudo, presume-se que abordar essa área da Fisioterapia, além de permitir e somar com outras pesquisas pode ter também uma significativa relevância no cenário da saúde brasileira, no que se refere à atuação do Fisioterapeuta esportivo em desenvolver um trabalho de reduzir e prevenir lesões, em atletas praticantes do Voleibol I.

\section{BIBLIOGRAFIA}

AAOS - American Academy of Orthaepedic Surgeons (AAOS). (2003). Pay attention to high school sports injuries. Disponível em: https://orthoinfo.aaos.org/en/diseases-conditions/high-school-sports-injuries/. Acesso em: I9 de Abr. 202I.

ALVES, R. N et al. Monitoramento e prevenção do supertreinamento em atletas. Rev Bras Med Esporte 2006;12(5):291-6. 
ANTÔNIO, V. S. Prevalência de lesões em atletas de voleibol feminino e possíveis relações com treinamento inadequado e estresse. Revista Hórus, vol 6, número I (Jan-Mar), 2012.

BEIJSTERVELDT, V; et al., Effectiveness of an injury prevention programme for adult male amateur soccer players: a cluster-randomised controlled trial. Br J Sports Med, ,v.46, n. I6, p. III4- III8, 2013.

CARDOSO, J. R. Influência da utilização da órtese de tornozelo durante atividades de voleibol: Avaliação eletromiográfica. Paraná: Rev. Bras. Med Esporte- Vol.II, N5Set/Out, 2005.

CBV. Confederação Brasileira De Voleibol. Histórico do Voleibol CBV. 2013. Disponível em: https://cbv.com.br>. Acesso em: i9 de Abr. 2021.

COHEN, M; ABDALLA, R. J. Lesões nos esportes - Diagnóstico, prevenção e tratamento. São Paulo: Revinter, 2003.

FERRETI, A. Volleybal Injuries A colour Atlas of Volleyball Traumatology. Federetion Intemationale de Volleyball, 1996.

GILCHRIST, J.; MANDELBAUM;BERT R.; MELANCON, H.; RYAN, GEORGE, W.; RYAN; SILVERS; HOLLY, J.; GRIFFIN; LETHA, Y.; WATANABE; DIANE, S.; DICK; RANDALL, W.; DVORAK, J. A randomized controlled trial to prevent noncontact anterior cruciate ligament injury in female collegiate soccer players. Am J Sports Med, Atlanta, v.36, n.8, p.I476-I483, 2008.

LANZA, B. B. B. Metodologia do Ensino de Educação Física. Curitiba. 2018.

MARQUES, M. A. F., et al. Identificação dos tipos de lesões no campeonato da II liga do interior de vôlei no estado do ceará. II congresso de Pesquisa e Inovação da rede norte de 
educação tecnológica, João Pessoa, 2007. Disponível em:

ttp://www.redenet.edu.br/publicacoes/arquivos/20080226_133419_. Acesso em: 23 de Abr. 2021.

MATIAS, Cristino Julio Alves da Silva; GRECO, Pablo Juan. O conhecimento tático declarativo dos levantadores campeões de voleibol. Motriz, Rio Claro, v.19 n.I, p.185-194, jan./mar. 2013. Disponível em: https://www.scielo.br/pdf/motriz/vigni/argvigni.pdf. Acesso em: 22 de Abr. 2021.

RESENDE, M.M.; CÂMARA, C. N.; CALLEGARI, B. Fisioterapia e prevenção de lesões esportivas. Fisioterapia Brasil, Belém, v.15, n.3, p.219-223, 2014. Disponível em: file://C:/Users/user/Downloads/343-Texto\%2odo\%20Artigo-I635-I-Io-20160714.pdf. Acesso em: I8 de Abr. 202I.

SILVA, A. A. et al. Analise do perfil, funções e habilidades do fisioterapeuta com atuação na área esportiva nas modalidades de futebol e voleibol no Brasil. Rev Bras Fisioter, São Carlos, v. 15, n. 3, p. 219-26, maio/jun. 2011.

TALMA, P. V. Prevalência de lesões osteomioarticulares em atletas de voleibol de quadra da UFJF. [Monografia] UFJF, Juiz de fora, 2009. 